\title{
PENGARUH HUBUNGAN BIG FIVE PERSONALITY, PERILAKU HIDUP SEHAT, DAN INDEKS MASSA TUBUH TERHADAP INTUITIVE EATING PADA SISWA SMA DI WILAYAH MALANG
}

\author{
Khoirotul Awwaliyah \\ khoirotul.awwaliyah@gmail.com \\ Anggota HIMPSI Provinsi Jawa Barat
}

\author{
Risatianti Kolopaking \\ risakolopaking@gmail.com \\ Fakultas Psikologi UIN Syarif \\ Hidayatullah Jakarta
}

\begin{abstract}
Intuitive eating is a form of eating behavior characterized by a strong connection to the physiological cues of hunger and satiety, taking into account the amount of body needs and the type of food to eat to maintain the nutritional and body health. The sampling technique is non probability sampling. A total of 263 adolescents aged 15 years to 19 years with the criteria of high school students who live in Malang, East Java and have got balanced nutrition education program be sample of this study. The results of this study show significant influence of personality extraversion, personality agreeableness, personality conscientiousness, personality neuroticism, personality openness to experiences of big five personality, healthy life behavior, and body mass index (IMT) on intuitive eating in high school students in Malang regency. (R-square $=0.066$, sig $=0.032)$. Hypothesis test results show that neuroticism of big five personality and body mass index (IMT) have significant influence to intuitive eating.
\end{abstract}

Keyword : intuitive eating, big five personality, health life \& body mass index

\begin{abstract}
Abstrak
Intuitive eating adalah suatu bentuk perilaku makan yang ditandai dengan hubungan yang kuat pada isyarat-isyarat fisiologis dari rasa lapar dan kenyang, dengan memperhatikan jumlah kebutuhan tubuh dan jenis makanan yang harus dimakan untuk menjaga kesehatan gizi dan bentuk tubuh. Teknik pengambilan sampel yang digunakan adalah non probability sampling. Sebanyak 263 remaja berusia 15 tahun sampai dengan 19 tahun dengan kriteria siswa SMA yang berdomisili di Kabupaten Malang, Jawa Timur. Dan sudah mendapat program pendidikan gizi seimbang. Hasil penelitian ini menunjukkan adanya pengaruh yang signifikan personality extraversion, personality agreeableness, personality conscientiousness, personality neuroticism, personality openness to experiences dari big five personality, perilaku hidup sehat, dan indeks massa tubuh (IMT) terhadap intuitive eating pada siswa SMA di Kabupaten Malang. (R-square $=0.066$, sig $=0.032$ ). Hasil uji hipotesis menunjukkan bahwa neuroticism dari big five personality dan indeks massa tubuh (IMT) mempunyai pengaruh signifikan terhadap intuitive eating.
\end{abstract}

Kata kunci: intuitive eating, big five personality, perilaku hidup sehat \& indeks massa tubuh

Diterima: 20 April 2017 Direvisi: 27 Mei 2017 Disetujui: 30 Juni 2017 


\section{PENDAHULUAN}

Perilaku makan merupakan faktor terpenting dalam memikirkan kesehatan nutrisi masyarakat khususnya remaja dimana makanan dikonsumsi setiap hari dan sepanjang hari. Sebagai makhluk hidup manusia membutuhkan makanan, untuk bertahan hidup, beraktivitas dengan sehat, beribadah dengan khusyu', menjaga keturunan, dan menjamin keberlangsungan hidupnya. Energi yang dihasilkan tubuh untuk beraktivitas didapatkan dari makanan yang dikonsumsi tergantung pada nilai gizi yang didapat dari makanan. Banyak remaja melakukan diet habishabisan atau sebaliknya makan berlebih, makan sembarangan, dan makan asal senang. Banyak orang yang menghabiskan makanan yang lezat namun itu merupakan makanan yang tidak sehat (Piernas \& Popkin, 2010; Verhoeven, Adriaanse, de Vet, Fennis, \& de Ridder, 2014).Remaja juga kurang memahami makanan yang baik bagi kesehatannya, sehingga kemampuan makan secara intuitive eating perlu diteliti untuk dapat menerapkan pendekatan perilaku makan secara intuitif. Sebagai pemenuhan energi dan nutrisi untuk melanjutkan keberlangsungan hidup. Dasar untuk memahami perilaku makan remaja dalam memperoleh makanannya dilihat dari faktor penentu dan definisi pengukuran perilaku tersebut. Termasuk membuat keputusan tentang kapan harus makan, yang mana makanan untuk dimakan, dan berapa banyak yang akan dimakan. Keputusan ini ditentukan sebagai isyarat internal seperti lapar, kenyang, dan craving (Cavanagh, K.V., Kruja, B., \& Forestell, C.A., 2014).

Pada penelitian ini peneliti bekerjasama dengan SEAMEO RECFON Universitas Indonesia, Poltekkes Kemenkes, Malang dan Fakultas Psikologi UIN Syarif Hidayatullah, Jakarta. Dimana responden remaja yang terdiri dari siswa SMA di Kabupaten Malang sudah menerima program pendidikan gizi seimbang untuk meningkatkan kemampuan remaja dalam memahami serta menyadari kebutuhan fisik tubuhnya. Untuk mengetahui peningkatan kemampuan dalam kesehatan pada remaja, peneliti melakukan evaluasi dan pengembangan dari pendidikan gizi yang sudah diberikan pada remaja.

Selain mengevaluasi pemahaman remaja terhadap program gizi seimbang, peneliti merasa remaja perlu mengetahui perilaku makan yang lebih adaptif untuk menghindari gangguan makan dimasa yang akan datang. Young (2010), menegaskan bahwa pemahaman yang baik pada sikap dan perilaku makan sehat dapat mencegah berkembangnya gangguan makan dimasa yang akan datang. Sangperm (2006) mengatakan perilaku makan yang sehat penting bagi remaja karena dapat membantu remaja memenuhi kebutuhan nutrisi, sehingga menghasilkan kesehatan dan kualitas hidup lebih baik pada masa remaja serta dewasa nanti. Selain itu, masa remaja adalah masa penting untuk menerapkan perilaku makan sehat karena perilaku makan yang terbentuk pada remaja akan bersifat menetap sampai dewasa (Ogden, 2003; Spear \& Kulbolk, 2001 dalam Sangperm, 2006).

Jika penelitian terdahulu lebih berfokus pada gangguan makan, maka penelitian kali ini fokus untuk meningkatkan keterampilan makan remaja yang lebih baik.Intuitive eating adalah suatu bentuk perilaku makan yang ditandai dengan hubungan yang kuat pada isyarat-isyarat fisiologis dari rasa lapar dan kenyang, dengan memperhatikan jumlah kebutuhan tubuh dan jenis makanan 
yang harus dimakan untuk menjaga kesehatan gizi dan bentuk tubuh (Tribole \& Resch, 1995; Tylka dan Wilcox, 2006; Tylka \& Kroon Van Diest, 2013). Artinya seseorang diperbolehkan untuk makan apapun tanpa batas sesuai respon yang diterima tubuh.

Menurut Tylka dan Kroon Van Diest (2013) intuitive eating terdiri dari empat unsur utama yaitu, unconditional permission to eat ketika lapar dan menginginkan makan, eating for pyshical rather than emotional reasons, reliance on internal hunger and satiety cues untuk memutuskan kapan dan berapa banyak jumlah yang dimakan, dan terakhir body food-choice congruence, atau mempergunakan gentle nutrition (nutrisi yang baik).

Dari perspektif intuitive eatingini, remaja dianggap mampu mengatur asupan makanan mereka dengan cara yang sehat, memakan apa yang mereka inginkan, kapan mereka menginginkannya, dimulai saat mereka lapar, dan berhenti saat mereka merasa kenyang. Ketika orang makan secara intuitive, umumnya mereka mengkonsumsi makanan bergizi lebih banyak dan mampu mempertahankan berat badan yang proposional dan sesuai jenis kelamin mereka (Enili, Crum \& Tylka, 2008; Moy, Petrie, Dockendorff, Greenleaf, \& Martin, 2013). Selain memenuhi kebutuhan energi dengan mengkonsumsi makanan, biasanya tingkat intuitive eating yang lebih tinggi dikaitkan dengan konsumsi makanan yang lebih besar (Anderson, Schaumberg, Anderson, \& Reilly, 2015).

Selanjutnya salah satu faktor internal yang memberikan pengaruh dalam menentukan intuitive eating pada remaja yaitu kepribadian, meskipun belum banyak penelitian yang mengarah pada personalitybig five hubungannya dengan intuitive eating namun dapat dijelaskan lebih lanjut pada penelitian MacLaren dan Best (2009) kaitannya dengan subtipe gangguan makan, secara keseluruhan hasilnya menunjukkan bahwa skor yang tinggi pada trait neuroticism memberi resiko pada berkembangnya gangguan makan.

Adanya gangguan makan berkembang karena akumulasi dari perilaku makan yang tidak sehat. Hal ini sejalan dengan penelitian Elfhag \& Morey (2008) secara konsisten penelitiannya menunjukkan trait neuroticism yang secara positif memprediksi perilaku makan yang tidak sehat, seperti makan secara emosional dan makan karena pengaruh eksternal. Khususnya sifat impulsive dan depresi (Heaven et al, 2001; Elfhag \& Morey, 2008) ketakutan, dan kerentanan emosional (Elfhag \& Morey, 2008) impulsiveness itu sendiri mengacu pada ketidakmampuan mengendalikan dan menahan keinginan, hasrat dan dorongan serta rendahnya toleransi pada frustasi (Piedmont, 1998; Elfhag \& Morey, 2008) dalam kaitannya dengan makan. Sedangkan extraversion, openness to experiences, conscientiousness, dan agreeableness berhubungan positif dengan perilaku makan sehat dan restrained eating. Extraversion berhubungan dengan aspek kehangatan, dan emosi positif. Openness to experiences berhubungan dengan estetika, perasaan dan perilakunya (Elfhag \& Morey, 2008).

Selain big five personality peneliti menduga bahwa perilaku hidup sehat danindeks massa tubuh (IMT) juga mempengaruhi intuitive eating. Masa remaja amat penting diperhatikan karena merupakan masa transisi antara anak-anak dan dewasa. Perilaku hidup sehat pada masa ini akan sangat menentukan kematangan mereka dimasa depan. Masa remaja adalah saat terjadinya perubahan-perubahan 
cepat, sehingga asupan zat gizi remaja harus diperhatikan benar agar mereka dapat tumbuh optimal. Apalagi di masa ini, aktivitas fisik remaja pada umumnya lebih banyak. Selain disibukkan dengan berbagai aktivitas sekolah, mereka juga mulai menekuni berbagai kegiatan, seperti olahraga, hobi, kursus. Semua itu tentu akan menguras energi, yang berujung pada keharusan menyesuaikannya dengan asupan gizi yang seimbang (Soekirman \& Afriansyah, 2014).

Salah satu penelitian Hawks et.al (2004) dalam mengembangkan the intuitive eating scale menemukan bahwa intuitive eating berhubungan secara negatif dengan indeks massa tubuh (IMT), perilaku gangguan makan dan diet restriktif pada populasi mahasiswa. Hawks, Madanat, Hawks dan harris (2005) meneliti hubungan antara intuitive eating dan berbagai indikasi kesehatan pada mahasiswi dan salah satunya menunjukkan bahwa intuitive eating secara signifikan berhubungan dengan IMT. Smith dan Hawks (2006) dalam penelitiannya menemukan bahwa skor intuitive eating berhubungan dengan skor IMT yang lebih rendah, serta lebih sedikit perilaku diet dan cemas terhadap makanan.

Dalam kaitannya dengan indeks massa tubuh (IMT), dasar pemikiran utama dari intuitive eating adalah secara akurat menginterpretasikan dan melekat pada feedback insting dalam menentukan jumlah dan jenis makanan yang dikonsumsi. Maka dari itu, dengan menghiraukan apakah intuitive eating dengan tegas menyertakan tujuan menormalkan berat badan atau tidaknya, intuitive eatingseharusnya berkorelasi dengan IMT yang lebih rendah (Van Dyke \& Drinkwater, 2013).

Bertitik tolak pada fenomena di atas, peneliti tertarik untuk meneliti big five personality, perilaku hidup sehat, dan indeks massa tubuh yang diprediksi berpengaruh terhadap intuitive eating. Oleh karena itu judul penelitian ini adalah "Pengaruh big five personality, perilaku hidup sehat, dan indeks massa tubuh terhadap intuitive eating pada siswa SMA di Kabupaten Malang".

\section{METODE PENELITIAN}

\section{Populasi, sampel dan teknik pengambilan sampel}

Populasi dalam penelitian ini adalah remaja berusia 15-19 tahun yang berdomisili di Kabupaten Malang, Jawa Timur. Pada penelitian ini, responden terdiri dari 263 responden. Teknik pengambilan sampel dalam penelitian ini adalah dengan cara nonprobability sampling, dengan kriteria responden yaitu siswa SMA (sederajat) yang sudah mendapat program pendidikan gizi seimbang.

\section{Instrumen Pengumpulan Data}

Instrumen Penelitian. Dalam penelitian ini peneliti menggunakan empat alat ukur:

\section{Skala Intuitive Eating}

Peneliti menggunakan skala the intuitive eating scale - 2 (IES-2)yang dikembangkan oleh Tylka \& Kroon Van diest (2013) dimana didalamnya mengukur unconditional permission to eat, eating for pyshical rather than emotional reasons, reliance on internal hunger and satiety cues, dan body food-choice congruence. Alat ukur ini terdiri dari 23 item. 


\section{Skala Big Five Personality}

Peneliti menggunakan skala Mini-International Personality Item Pool (Mini-IPIP), yang dikembangkan oleh Donnellan, Oswald, Baird, dan Lucas, (2006). Dimana didalamnya mengukur Lima trait kepribadian, extraversion, agreeableness, conscientiousness, neuroticism, dan openness to experiences. Alat ukur ini terdiri dari 20 item.

\section{Skala Perilaku Hidup Sehat}

Dalam penelitian ini peneliti mengambil data dari program yang sudah berjalan dan dilakukan oleh tim peneliti SEAMEO RECFON Universitas Indonesia, Poltekkes Kemenkes, Malang dan Fakultas Psikologi UIN Syarif Hidayatullah, Jakarta. Dalam program ini tim peneliti ingin mengevaluasi pendidikan gizi seimbang yang telah diberikan kepada siswa, oleh karena itu alat ukur perilaku hidup sehat dalam penelitian ini disusun dan disarikan dari buku Pedoman Gizi Seimbang, Kementrian Kesehatan RI, 2014. Alat ukur ini terdiri dari 15 item.

\section{Skala Indeks Massa Tubuh}

Dalam penelitian ini penggukuran skala indeks massa tubuh didapat dari penghitungan berat badan dalam $\mathrm{kg}$ dibagi tinggi badan dalam $\mathrm{m}^{2}$. Dimana pengukuran ini dilakukan oleh nutrisionistdengan menggunakan timbangan badan dan microtoise staturmeter.

\section{HASILPENELITIAN}

\section{Gambaran Subyek Penelitian}

Subjek yang terlibat dalam penelitian ini sebanyak 263 responden dengan karakteristik siswa SMA (sederajat) yang sudah mendapat program pendidikan gizi seimbang. Adapun untuk lebih jelas sampel dalam penelitian ini siswa SMA kelas X berjumlah 197 orang (74.9\%) sedangkan siswa SMA kelas XI berjumlah 66 orang $(25.1 \%)$. Selanjutnya berdasarkan usia responden, dapat diketahui bahwa mayoritas responden berusia 16 tahun dengan jumlah 159 orang (60.5\%). Berdasarkan jenis kelamin dapat dikatakan jumlah responden perempuan berjumlah 141 orang (53.6\%) lebih banyak dibandingkan responden laki-laki dengan jumlah 122 orang (46.4\%). Sedangkan pada IMT responden mendapat nilai mean sebesar 21.2947 (3.93015).

\section{Uji Regresi}

\section{Tabel 1}

Uji regresi bersama big five personality, perilaku hidup sehatdan indeks massa tubuh terhadap intuitive eating

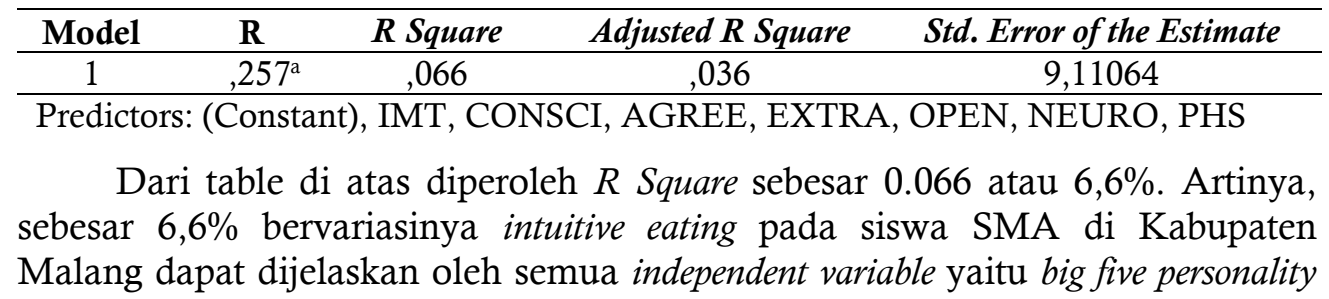


(extraversion, agreeableness, conscientiousness, neuroticism, openness to experiences), perilaku hidup sehat dan indeks massa tubuh sedangkan 92,4 \% lainnya dijelaskan oleh variabel lain di luar penelitian ini.

\section{Pengaruh keseluruhan IV terhadap DV}

\section{Tabel 2}

Uji signifikansi regresi dari big five personality, PHS dan IMT terhadap intuitive eating

ANOVA $^{\mathrm{a}}$

\begin{tabular}{llcclcc}
\hline & Model & Sum of Squares & $d f$ & Mean Square & F & Sig. \\
\hline 1 & Regression & 1301,096 & 6 & 185,871 & 2,239 &, $032^{\mathrm{b}}$ \\
& Residual & 18426,849 & 256 & 83,004 & & \\
& Total & 19727,945 & 262 & & & \\
\hline
\end{tabular}

a. Dependent Variable: IES

b. Predictors: (Constant), IMT, AGREE, CONSCI, OPEN, EXTRA, NEURO, PLS14

Berdasarkan uji $\mathrm{F}$ pada table di atas, dapat dilihat bahwa nilai p (sig.) pada kolom paling kanan adalah $\mathrm{p}=0.032<0.05$, maka hipotesisi nihil yang menyatakan tidak ada pengaruh yang signifikan dari seluruh independen variabel terhdapa intuitive eating ditolak. Artinya, ada pengaruh yang signifikan dari big five personality extraversion, agreeableness, conscientioueness, neuroticism, openness to experiences, perilaku hidup sehat, dan indeks massa tubuh terhadap siswa SMA di Kabupaten Malang, Jawa Timur. Dengan ketentuan, jika t > 1.96 atau nilai signifikansi $\mathrm{p}<0.05$, maka koefisien regresi tersebut signifikan, berarti independent variabel tersebut memiliki pengaruh yang signifikan terhadap intuitive eating pada siswa SMA di Kabupaten Malang, Jawa Timur.

Selanjutnya adapun persamaan regresi dari penelitian ini yaitu :

Intuitive Eating $=62.933+-0.131$ Extraversion +-0.021 Agreeableness +0.087 Conscientiousness +-0.238 Neuroticism +-0.024 Openness to experiences +-0.059 perilaku hidup sehat +0.304 indeks massa tubuh.

Dari persamaan diatas dapat dilihat bahwa delapan variabel IV, yang berdampak signifikan terhadap DV yaitu neuroticismdan indeks massa tubuh, sisanya tidak signifikan terhadap DV. Kemudian nilai koefisien regresi yang diperoleh dari masing-masing independent variable adalah sebagai berikut:

1. Variabel Extraversion memiliki koefisien regresi sebesar -0,131 dengan nilai $\mathrm{p}$ sebesar 0.093 (sig. > 0.05), artinya variabel extraversion tidak berpengaruh secara signifikan terhadap intuitive eating.

2. Variabel Agreeablenessmemiliki koefisien regresi sebesar -0,021 dengan nilai $\mathrm{p}$ sebesar 0.793 (sig. > 0.05), artinya variabel agreeablenesstidak berpengaruh secara signifikan terhadap intuitive eating.

3. Variabel Conscientiousness memiliki koefisien regresi sebesar 0,087 dengan nilai p sebesar 0.288 (sig. $>0.05$ ), artinya variabel conscientiousness tidak berpengaruh secara signifikan terhadap intuitive eating. 
4. Variabel Neuroticism memiliki koefisien regresi sebesar $-0,238$ dengan nilai $\mathrm{p}$ sebesar 0.007 (sig. < 0.05), artinya variabel neuroticism memiliki pengaruh yang signifikan negatif terhadap intuitive eating. Hal ini menunjukkan bahwa semakin tinggi kepribadian neuroticismsiswa maka akan semakin rendah sikap intuitive eating.

5. Variabel Openness to experiences memiliki koefisien regresi sebesar $-0,024$ dengan nilai $\mathrm{p}$ sebesar 0.771 (sig. $>0.05$ ), artinya variabel openness to experiences tidak berpengaruh secara signifikan terhadap intuitive eating.

6. Variabel Perilaku Hidup Sehat memiliki koefisien regresi sebesar -0.059 dengan nilai $\mathrm{p}$ sebesar 0.434 (sig. $>0.05$ ), artinya variabel perilaku hidup sehat tidakmemiliki pengaruh yang signifikan terhadap intuitive eating.

7. Variabel Indeks Massa Tubuh memiliki koefisien regresi sebesar 0.304 dengan nilai p sebesar 0.046 (sig. < 0.05), artinya variabel IMT memiliki pengaruh yang signifikan terhadap intuitive eating. Hal ini menunjukkan bahwa semakin tinggi skor IMT maka akan semakin tinggi sikap intuitive eating.

Untuk Lebih jelas bisa melihat tabel di bawah ini.

Tabel 3

Multiple regresi dari pengaruh $I V$ terhadap $D V$

\begin{tabular}{|c|c|c|c|c|c|}
\hline Model & B & $\begin{array}{c}\text { Unstandardized } \\
\text { Coefficients } \\
\text { Std. Error }\end{array}$ & $\begin{array}{c}\text { Standardized } \\
\text { Coefficients } \\
\text { Beta }\end{array}$ & $\mathrm{t}$ & Sig. \\
\hline (Constant) & 62,933 & 8,489 & & & \\
\hline EXTRA &,- 131 & 078 &, 118 & $-1,686$ & ,093 \\
\hline AGREE &,- 021 & ,082 &,- 018 &,- 263 & ,793 \\
\hline CONSCI & 087 & 082 &, 076 & 1,064 & ,288 \\
\hline NEURO &,- 238 & 087 &, 188 & $-2,743$ & 007 \\
\hline OPEN &,- 024 & 082 &,- 020 &,- 292 &, 771 \\
\hline PHS & -,059 & 076 &,- 056 & $\begin{array}{l}-, 784 \\
-, 74\end{array}$ &, 434 \\
\hline IMT & ,304 & 152 & , 132 & 2,002 &, 046 \\
\hline
\end{tabular}

a. Dependent Variable: IES

\section{Kesimpulan}

\section{KESIMPULAN DAN SARAN}

Berdasarkan hasil analisis data yang telah dilakukan, terdapat pengaruh bersama yang signifikan dari variabel big five personality (extraversion, agreeableness, conscientiousness, neuroticism, dan openness to experiences), perilaku hidup sehat dan indeks massa tubuh terhadap intuitive eating siswa SMA. Variabel yang memiliki pengaruh signifikan terhadap intuitive eating berdasarkan urutan yang paling besar yaitu neuroticism kemudian indeks massa tubuh. Variabel neuroticism memiliki pengaruh signifikan yang negatif terhadap intuitive eating. Sedangkan variabel indeks massa tubuh memiliki pengaruh signifikan yang positif terhadap intuitive eating. 


\section{Diskusi}

Pada penelitian ini sebagian siswa SMA (54.8\%) diketahui memiliki skor intuitive eating yang tinggi. Artinya siswa memiliki kesiapan dalam merespon sinyal dari rasa lapar dan kenyang dalam tubuhnya. Mereka menggunakan isyarat ini untuk menentukan kapan dan seberapa banyak mereka harus makan serta memperbolehkan diri untuk makan apapun tanpa batas sesuai respon yang diterima tubuh. Siswa dengan skor intuitive eating tinggi akan menjaga kecocokan antar pilihan makanan dengan kebutuhan tubuh seperti memilih makanan yang bernutrisi dapat meningkatkan tenaga, stamina dan performa tubuh. Siswa juga cenderung memilih makan untuk memenuhi kepentingan tubuh daripada kebutuhan emosional. Sedangkan sekitar 45.2\% siswa SMA masih memiliki intuitive eating yang rendah. Sehingga diperlukan perhatian untuk meningkatkan keterampilan makan yang baik pada siswa agar bisa menerapkan perilaku makan sesuai dengan pedoman gizi seimbang untuk meningkatkan intuitive eating pada siswa.

Hasil penelitian menunjukkan bahwa intuitive eating pada penelitian ini dipengaruhi oleh big five personality dan indeks massa tubuh. Ditemukan bahwa neuroticism dari big five personality dan indeks massa tubuh mempengaruhi intuitive eating secara signifikan.Kepribadian neuroticism memiliki pengaruh negatif yang signifikan terhadap intuitive eating, hal ini menunjukkan bahwa semakin tinggi kepribadian neuroticism siswa maka akan semakin rendah sikapintuitive eatingyang dimiliki oleh siswa. Dalam penelitian ini ditemukan bahwa sebagian siswa SMA sebanyak 52.1\% memiliki neuroticism yang tinggi. Artinya, sebagian siswa dalam penelitian ini memiliki masalah dengan emosi yang negatif seperti rasa khawatir dan rasa tidak aman. Secara emosional mereka labil, mereka mengubah perhatian menjadi sesuatu yang berlawanan.

Siswa dengan neuroticism yang tinggi cenderung bereaksi berlebihan secara emosional, mudah mengalami kecemasan, kemarahan (tempramental), depresi, memiliki kesulitan dalam menjalin hubungan dan komitmen. Semakin tinggi nilai neuroticism membuat siswa kurang memiliki intuitive eating. Akhirnya siswa makan dengan kurang kesadaran, makan semaunya, makan berlebih, maupun tidak makan sama sekali. Dan siswa tidak menyadari sinyal respon rasa lapar dari dalam tubuhnya untuk menentukan kapan dan seberapa banyak mereka harus makan. Hasil penelitian ini sejalan dengan penelitian Elfhag \& Morey (2008) secara konsisten penelitiannya menunjukkan trait neuroticism yang secara positif memprediksi perilaku makan yang tidak sehat, seperti makan secara emosional dan makan karena pengaruh eksternal. Siswa dengan skor neuroticism tinggi tidak menyadari sinyal respon rasa lapar dari dalam tubuhnya untuk menentukan kapan dan seberapa banyak mereka harus makan.

Sedangkan untuk variabel Indeks massa tubuh pada hasil penelitian memiliki pengaruh positif yang signifikan terhadap intuitive eating. Hal ini menunjukkan bahwa semakin tinggi skor IMT maka akan semakin tinggi sikap intuitive eating yang dimiliki oleh siswa. Dalam penelitian ini ditemukan bahwa siswa SMA sebanyak $73.4 \%$ memiliki IMT normal, dengan nilai rata-rata 21.2947. Hal ini menunjukkan bahwa siswa yang memiliki berat badan normal akan memiliki perilaku intuitive eating yang baik. Siswa dengan IMT normal 
memiliki keterampilan untuk menentukan makanan apa yang tepat dalam menanggapi kebutuhan fisik internal dirinya.

Hasil penelitian ini sejalan dengan penelitian Hawks, Madanat, Hawks dan Harris (2005) dimana mereka meneliti hubungan antara intuitive eating dan berbagai indikasi kesehatan pada mahasiswi dan salah satunya menunjukkan bahwa intuitive eating secara signifikan berhubungan dengan IMT. Smith dan Hawks (2006) dalam penelitiannya menemukan bahwa skor intuitive eating berhubungan negatif dengan skor IMT yang lebih rendah, dimana mereka yang memiliki IMT rendah cenderung memiliki perilaku diet dan cemas terhadap makanan.

Dalam penelitian ini terdapat variabel yang tidak signifikan terhadap intuitive eating. Yaitu, extraversion, conscientiousness, agreeableness, openness to experiences, dan perilaku hidup sehat. Variabel extraversion dan agreeableness yang merupakan variabel dari big five personality memiliki pengaruh signifikan yang negatif terhadap intuitive eating. Hal ini menunjukkan bahwa semakin tinggi kepribadian extraverion dan agreeableness siswa maka akan semakin rendah sikap intuitive eating yang dimiliki oleh siswa. Sebagian siswa dalam penelitian ini (54.4\%) berada dalam kategori rendah, artinya siswa yang memiliki antusias tinggi, senang bergaul, energik, ramah, pemaaf dan penyayang lebih sedikit. Akibatnya siswa makan dengan kurang kesadaran, makan semaunya, makan berlebih, maupun tidak makan sama sekali. Dan siswa tidak menyadari sinyal respon rasa lapar dari dalam tubuhnya untuk menentukan kapan dan seberapa banyak mereka harus makan. Hasil penelitian ini sejalan dengan penelitian Elfhag \& Morey (2008) siswa dengan kepribadian extraverion dan agreeableness tinggi cenderung memantau dan membatasi asupan makan mereka dalam rangka untuk mengontrol berat badan.

Variabel kepribadian conscientiousness yang merupakan variabel dari big five personality memiliki pengaruh signifikan yang positif terhadap intuitive eating. Hal ini menunjukkan bahwa semakin tinggi kepribadian conscientiousness maka akan semakin tinggi sikapintuitive eating yang dimiliki oleh siswa. Sebagian siswa dalam penelitian ini $(54.0 \%)$ berada dalam kategori conscientiousnessyang tinggi, artinya terdapat banyak siswa yang memiliki sikap disiplin, teratur, dan rapih. Dengan kata lain, siswa dengan conscientiousness tinggi memiliki keterampilan makan yang baik. Siswa mampu mengendalikan perilaku makan mereka, dan mampu memantau asupan makanan yang disesuaikan dengan kebutuuhan tubuh mereka. Namun kepribadian conscientiousness tidak signifikan dengan intuitive eating dalam penelitian ini. Sesuai dengan penelitian Elfhag \& Morey (2008) bahwa siswa dengan kepribadian conscientiousness cenderung lebih restrained eating.

Variabel openness to experiences yang merupakan variabel dari big five personality memiliki pengaruh signifikan yang negatif terhadap intuitive eating. Hal ini menunjukkan bahwa semakin tinggi kepribadian openness to experiences siswa maka akan semakin rendah sikap intuitive eating yang dimiliki oleh siswa. Sebagian siswa dalam penelitian ini $(56.3 \%)$ berada dalam kategori rendah, artinya terdapat banyak siswa yang mempunyai pemikiran sempit, konservatif, dan tidak terlalu penasaran terhadap sesuatu. Akibatnya siswa makan dengan kurang kesadaran, makan semaunya, makan berlebih, maupun tidak makan sama 
sekali. Dan siswa tidak menyadari sinyal respon rasa lapar dari dalam tubuhnya untuk menentukan kapan dan seberapa banyak mereka harus makan. Hasil penelitian ini sejalan dengan penelitian Elfhag \& Morey (2008) siswa dengan kepribadian openness to experiences rendah cenderung kurang memantau dan membatasi asupan makan. Kemampuan mereka untuk memonitor asupan kalori mereka sangatlah lemah.

\section{Saran}

Pada penelitian ini ditemukan bahwa proporsi varians dari intuitive eating pada siswa SMA di Kabupaten Malang yang dijelaskan oleh semua IV adalah sebesar $6,6 \%$, sedangkan $92,4 \%$ sisanya dipengaruhi oleh variabel lain di luar penelitian ini, maka penulis menyarankan untuk penelitian selanjutnya agar meneliti dan menganalisis pengaruh variabel di luar variabel yang telah diteliti agar lebih luas dalam gambaran penelitiannya.

\section{DAFTAR PUSTAKA}

Allport, G. W., \& Odbert, H. S. (1936). Trait-names: A psycho-lexical study. Psychological monograph, 47(1), 1936, i-171. Retrieved from psycnet.apa.org tanggal 22 Mei 2017.

Anderson, D. A., Schaumberg, K., Anderson, L. M., \& Reilly, E. E. (2015). Is level of intuitive eating associated with plate size effects?.Eating Behaviors, $18,125-130$.

Augustus-Hovarts, C. L., \& Tylka, T. L. (2011). The acceptance model of intuitive eating: A comparison of women in emerging adulthood, early adulthood, and middle adulthood. Journal of Counseling Psychology, 105(6), 929-936.

Avalos, L. C., \& Tylka, T. L. (2006). Exploring a Model of Intuitive eating with College Women. Journal of Counseling Psychology, 53(4), 486-497.

Bardone-cone, A. M., Wonderlich, S. A., Frost, R. O., Bulik, C. M. Mitchell, J. E., Uppala, S., \& Simonich, H. (2007). Perfectionism and eating disorders: Current status and future directions. Clinical Psychology Review, 27, 384405.

Birch, L. L. (1999). Development of food preferences. Annual review of nutrition, 71(5), 1054-1061.

Cavanagh, K.V., Kruja, B., \& Forestell, C.A. (2014). The effect of brand and caloric information on flavor perception and food consumption in restrained and restrained eaters. Appetite. 82, 17.doi:10.1016/j.appet.2014.06.100.

Centers for Disease Control and Prevention. (2017). About BMI for children and teens.http://www.cdc.gov/healthyweight/assessing/bmi/children bmi/a boutchilddrensbmi.html. Diakses pada tanggal 24 April 2017

Donellan, M.B., Oswald, F.L., Baird, B.M., \& Lucas, R.E. (2006). The miniIPIP scale: tiny-yet-effective measure of the big five factors of personality. Psychological assesment. The American Psychological Association, 18(2), 192203Research in Personality, 37, 319-338 
Elfhag, K., \& Morey, L. C. (2007). Personality traits and eating behavior in the obese: Poor self-control in emotional and external eating but personality assets in restrained eating. Eating Behaviors, 9, 285-293.

Elsner, R. J. F. (2002). Changes in eating behavior during the aging process. Eating Behaviors, 3, 15-43.

Feist, J \& Feist, G. (2008). The theories of personality-7th ed. New York: McgrawHill Companies.

Friedman \& Schustack. (2008). Kepribadian: Teorii klasik dan riset modern. Jakarta: Erlangga.

Furman E. F. (2012). The theory of compromised eating behavior. Dissertations. University of Massachusetts, Amherst.

Hawks, S., Madanat, H., Hawks, J., \& Harris, A. (2005). The relationship between intuitive eating and health indicators among college women. Journal of Health Education, 36(6), 331-336.

Hawks, S., Merrill, R.M., \& Madanat, H. N. (2004). The intuitive eating scale: Development and preliminary validation. American Journal of Health Education, 35(2), 90-99.

Hill, A. J., Oliver, S., \& Rogers, P. J. (1992). Eating in adult world: The rice of dieting in childhood and adolescence. British Journal of clinical psychology, 31, 95-105.

Hurlock, E. (1980). Psikologi Perkembangan. Jakarta: Erlangga.

Ikatan Dokter Anak Indonesia. (2015). Nutrisi Pada Remaja: Bunga Rampai Kesehatan Remaja. www.idai.or.id/artikel/seputar-kesehatananak/nutrisi-pada-remaja. Diunduh tanggal 11 November 2015.

Jahja, Y. (2011). Psikologi Perkembangan. Jakarta: Kencana

Kemenkes RI. (2014). Pedoman Gizi Seimbang. Jakarta.

Kussoy, K., Fatimawali, \& Kepel, B. (2013). Prevalensi Obesitas Pada Remaja Di Kabupaten Minahasa. Fakultas Kedokteran Universitas Sam Ratulangi; Manado. e-Biomedik, Vol. 1, No. 2, Juli 2013.

MacLaren, V.V., \& Best, L. A. (2009). Female Students' Disordered Eating and the Big Five Personality Facets. Eating Behaviors. 10 (2009) 192-195.

Mayer, J. D. (2007). Asserting the Definition of Personality. The Online Newsletter for Personality Science. Issue 1, spring 2007.

McLaughlin, A., \& Media, D. (2014) Short Term Effect of Bad Eating Habits. Healthyeating.sfgate.com; diakses pada tanggal 27 April 2016

Moy, J., Petrie, T. A., Dockendorff, S., Greenleaf, C., \& Martin, S. (2013). Dieting, exercise, and intuitive eating among early adolescents. Eating Behaviors, 14, 529-532.

Sangperm, P. (2006). Predicting Adolescent Healthy Eating Behavior Using Attitude, Subjective Norm, Intention, and Self-Schema. Thesis, Faculty of Graduate Studies Mahidol University.

Sarwono, S. W., Meinarno, E. A., dan Tim Penulis Fakultas Psikologi UI. (2011) Psikologi Sosial. Jakarta: Salemba Humanika.

Smolak, L., Levine, M. P., \& Schermer, F. (1999). Parental input and weight concerns among elementary school children. International journal of Eating Disorders. 25(3) 263-271. Retrieved fromhttp://onlinelibrary.wiley.com/ 
Soekirman, \& Afriansyah, N. (Eds.). 2010. Sehat dan Bugar Berkat Gizi Seimbang. Nakita; Jakarta.

Tondang, L. M., dan Nasution S. Z. 2012. Pengetahuan Dan Sikap Remaja Tentang Perilaku Hidup Sehat Di Panti Asuhan Evangeline Booth Dan Asrama Madani. Fakultas Keperawatan, Universitas Sumatera Utara. Diakses pada tanggal 20 Agustus 2017 dari laman https://jurnal.usu.ac.id/

Tylka, T. L., \& Kroon Van Diest, A. M. (2013). The Intuitive Eating Scale-2: Item refinement and psychometric evaluation with college women and men. Journal of Counseling Psychology, 60(1), 137-153.

Tylka, T. L., \& Wilcox, J. A. (2006). Are Intuitive Eating and Eating Disorder Symptomatology Opposite Poles of the Same Construct? Journal of Counseling Psychology, 53(4), 474-485.

Van Dyke, N., \& Drinkwater, E. J. (2013). Review Article Relationships between Intuitive Eating and Health Indicators: literature review. Public health nutrition, 1-10.

Verhoeven, A.A.C, Adriaanse, M.A, de Vet, E., Fennis, B.M., \&de Ridder, D.T.D. (2014) it's my party and I eat if I want to. Reasons for unhealthy snacking. Utrecht University, Netherlands. Appetite 84 (2014) 20-17

Young, S. K. (2010). Promoting healthy eating among college women: Effectiveness of an intuitive eating intervention. Doctoral disertation. Iowa state university. 